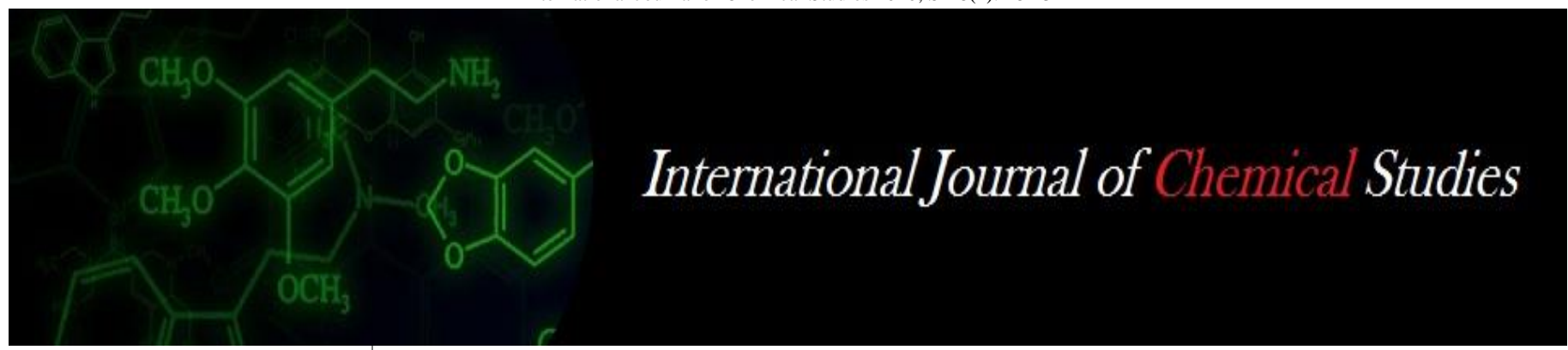

P-ISSN: 2349-8528

E-ISSN: 2321-4902

www.chemijournal.com

IJCS 2020; SP-8(4): 18-23

(C) 2020 IJCS

Received: 14-05-2020

Accepted: 15-06-2020

Oinam Roselyn Devi

Department of Apparel and

Textile Science, Punjab

Agricultural University,

Ludhiana, Punjab, India

Dr. Sandeep Bains

Department of Apparel and

Textile Science, Punjab

Agricultural University,

Ludhiana, Punjab, India

Dr. Sumeet Grewal

Department of Apparel and

Textile Science, Punjab

Agricultural University,

Ludhiana, Punjab, India
Corresponding Author: Oinam Roselyn Devi

Department of Apparel and

Textile Science, Punjab

Agricultural University,

Ludhiana, Punjab, India

\section{Comparative study of ultrasonic and conventional dyeing of cotton and wool with natural dye arjun (Terminalia arjuna) bark}

\author{
Oinam Roselyn Devi, Dr. Sandeep Bains and Dr. Sumeet Grewal
}

DOI: https://doi.org/10.22271/chemi.2020.v8.i4a.9811

\begin{abstract}
Traditionally, the conventional dyeing method is an energy-intensive process as the dyeing is carried out above $100^{\circ} \mathrm{C}$ to obtain good color strength and color fastness properties. Furthermore, these high temperatures may deteriorate the fabric surface. Ultrasonic dyeing method is an alternative method of conventional dyeing of textile materials, providing energy saving by reduced process temperature and time. This paper focuses on comparing the conventional and ultrasonic dyeing methods of cotton and wool fabrics with natural dye arjun bark to investigate the effect of ultrasonic waves on dyeing performance. The effect of ultrasonic wave on the dyeing properties was studied after comparing the K/S value, the CIE Lab values and the color fastness properties of both the conventional and the ultrasonic dyed samples. Experimental results indicated that the ultrasonic dyeing method gave better color strength, deeper dye diffusion and improved fastness properties as compared to the conventional dyeing method. Hence, taking into consideration the growing environmental concerns and to make the process of natural dyeing truly eco-friendly, ultrasonic dyeing may be regarded as an effective alternative to conventional natural dyeing method.
\end{abstract}

Keywords: Arjun bark, conventional, color strength, fastness, ultrasonic waves

\section{Introduction}

In recent past, the revival of colorants from natural sources such as plants, insects/animals and microbes had been gaining popularity. These colorants have been studied in relation to their application in different fields. Research into introduction of new natural dyes along with ecofriendly and cost-effective technologies for their processing and application has greatly expanded the scope of natural dyes in various fields (Anna and Christian, 2003; Ferreira et al, $2004)^{[1-2]}$. Synthetic dyes have been used greatly in textile industry as dyeing material because of production of wide range of shades, brilliant colors, good color fastness properties, low cost and ease of use. However, the synthetic dyes sometimes produce allergic, toxic and carcinogenic by-products which are harmful to human health (Ali et al, 2013) ${ }^{[3]}$. The use of these products has been declining in the textile industry because of the restriction imposed by many environmental bodies and associations. On the other hands, natural dyes are non-toxic, biodegradable, having no hazardous effect on human health and also more economical over synthetic dyes.

Majority of natural dyes need mordants at the time of dyeing to improve the color strength and color fastness of the fabrics. Mordants acts as a binder and form a chemical bridge between the dyes to the fabric and thus improve the dyeability and increase the fastness properties (Padma, 2000) ${ }^{[4]}$. The basic purpose of extraction is to produce maximum required colorant. Traditionally, extraction methods are done by heating or boiling. Although these methods are eco-friendly, they are time consuming, expensive and require large amount of labor. Many new dyeing techniques such as ultraviolet, microwave, ultrasonic, plasma, and gamma radiations have been introduced and provide a positive effect in natural dyeing process (Adeel et al, 2016; Baaka et al, 2017; Haji et al, 2016; Adeel et al, 2017) ${ }^{[5-8]}$. Among these techniques, ultrasonic radiation is considered as a convenient and energy saving method (Wang et al, 2013) ${ }^{[9]}$. It also improves the dye uptake and lowers the processing time using low temperatures because the ultrasonic waves break the dye aggregates, stabilized the dispersion and accelerates the rate of the diffusion inside the fibre. Being wider wave uniform 
and more effective source of energy, ultrasonic treatment has been widely used in textiles (Asma et al, 2015; Mansour and Heffernan, 2013) ${ }^{[10-11]}$.

Keeping in view such advantages, the current study has been conducted to study the effect of ultrasonic wave on dyeing of cotton and wool fabrics using Arjun tree (Terminalia arjuna) bark. Terminalia arjuna belongs to family Combretaceae and its bark is greatly used in Ayurveda as well as Yunani systems of medicine (Sinha et al, 2016) ${ }^{[12]}$. Tannins, triterpenoid, saponin, arjunic acid, arjunolic acid, arjungenin, and arjunglycosides are the main phytochemicals present in Arjun bark (Mandal et al, 2013) ${ }^{[13]}$. Arjun plant has medicinal values and acts as anti- dysenteric anti- pyretic, astringent, cardiotonic, lithotriptic, anticoagulant, hypolipidemi, antimicrobial and antiuremic agents (Mandal et al, 2010; Das et al, 2010) ${ }^{[14-15]}$. It is also considered as an alternative for harmful brown synthetic dyes. The main coloring components are biacalein and ellagic acid (structure given below) which play their role in coloration of natural fiber.<smiles>O=c1cc(-c2ccccc2)oc2cc(O)c(O)c(O)c12</smiles>

Biacalein

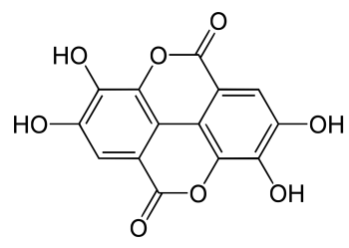

Ellagic acid
In this present work, the dyeing ability and color fastness properties of natural dye extracted from arjun bark on cotton and wool using ultrasonic wave will be compared with conventional natural dyeing method.

\section{Materials and Methods \\ Collection of Dyestuff}

Bark of Arjun tree (Terminalia arjuna) were collected from Punjab Agricultural University, finely ground and powdered to extract the dye.

\section{Optimization of dye extraction by ultrasonic method}

Different temperature $\left(30,45\right.$ and $\left.60^{\circ} \mathrm{C}\right), \mathrm{pH}(4,5,6,7$, and 8) and time $(15,30,45$ and $60 \mathrm{~min})$ were optimized to study the efficient extraction of dye. Dye material of $1 \mathrm{gm}$ each was measured and poured in deionized water of $50 \mathrm{ml}$. The solution was kept in ultrasonic bath for 45 minutes, maintaining temperature of $45^{\circ} \mathrm{C}$. Each extract was then strained through filter paper. Dye solution of $0.2 \mathrm{ml}$ each was taken out from dye bath and diluted 100 times. The diluted dye solution was then centrifuged at $3000 \mathrm{rpm}$ for 20 minutes. The dye solution was poured in the cuvette to measure the optical density of each dye solution extracted with the help of a spectrophotometer. The dye solution giving maximum optical density was taken as the optimum value for the extraction.

\section{Selection of fabric}

100 percent plain woven cotton and wool fabrics were purchased from local market of Ludhiana, Punjab, India.

\section{Mordants}

The natural mordants used included amla (Embilica officinalis) fruit and babool (Acacia nilotica) bark. These were selected because of their high tannin content. Laboratory grade chemicals such as tannic acid and alum were used as synthetic mordants and supplied by Thames chemical, Ludhiana.

\section{Pretreatment of samples}

The cotton and wool were scoured in order to remove the impurities which were present on the surface of the fabric. The cotton was soaked in 0.5 percent warm solution of nonionic surfactant (liquid detergent) for $3 \mathrm{hrs}$, keeping MLR 1:30. Whereas, wool was soaked for 45 minutes. After kneading and squeezing, they were rinsed and dried in shade. Since cotton had less affinity towards natural dyes, therefore, pre-treatment was required for cotton. Myrobalan fruit powder was selected for giving pre-treatment to cotton as the tannin content present in it aids in enhancement of dye uptake and fixing of dye on the fabric. The cotton was treated with 20 per cent of myrobalan, soaked for overnight, squeezed and lastly dried in the sun (Prabhavathi et al, 2014) ${ }^{[16]}$.

Optimization of dyeing variables by ultrasonic methods Optimization of dyeing of cotton and wool fabrics were studied at different dyeing concentration $(1,2,3,4,5 \mathrm{~g} / \mathrm{g})$, time $(15,30,45$ and $60 \mathrm{~min}), \mathrm{pH}(4,5,6,7,8,9)$ and temperature $\left(30,40,50\right.$ and $\left.60^{\circ} \mathrm{C}\right)$. After dyeing, the $\mathrm{K} / \mathrm{S}$ value was calculated and based on the color strength; the optimum dyeing concentration, time, $\mathrm{pH}$ and temperature were selected.

Different mordant concentration of amla and babool $(0.1,0.2$, $0.3,0.4$ and $0.5 \mathrm{~g})$, tannic acid $(1,2,3,4$ and $5 \mathrm{~g} / 100 \mathrm{~g}$ of fabric) and alum $(5,10,15,20$ and $25 \mathrm{~g} / 100 \mathrm{~g}$ of fabric were also optimized.

The optimum dyeing values of conventional dyeing techniques were taken from the previous research work for comparison. (Bains et al 2002; Bains et al 2002) ${ }^{[17-18] .}$

\section{Conventional dyeing method}

To compare the conventional and ultrasonic dyeing method and assess the fastness properties of two methods, the cotton and wool fabrics were dyed with four different mordants using both ultrasonic and conventional methods. The conventional dyeing of cotton and wool fabrics were done as described by Bains et al, $2006^{[19] .}$

\section{Ultrasonic dyeing methods}

The optimized value of dye material was extracted separately for cotton and wool fabric, at the optimum dye extraction $\mathrm{pH}$, for optimum time and maintained the optimum temperature. To obtain clear fitrate, each extract was strained through four layers of muslin cloth. The extracted dye solution was poured in the ultrasonic bath and maintained the MLR of 1:250. A fabric strip / pre-soaked sample was fixed on a stainless steel frame and immersed into the dye solution and subjected to ultrasound at optimized temperature for optimized time. The simultaneous mordanting method was performed at optimized mordant concentration. After dyeing, the baths were allowed to cool down for some time to avoid sudden change during rinsing. The samples were taken out, washed in mild detergent solution and rinsed in tap water to remove unfixed dye material. After thoroughly rinsing, the samples were finally dried in shade and further measured the color strength and fastness properties. 


\section{Color strength}

The reflectance and color strength of the dyed sample was measured using Colorflex Hunter Lab. The color strength values are calculated using the following "Kulbelka - Munk" equation:

$\mathrm{K} / \mathrm{S}=\frac{(1-R)^{2}}{2 R}$

Where $\mathrm{K}$ is the absorption co-efficient, $\mathrm{R}$ is the decimal fraction of the reflectance of dyed fabric and $\mathrm{S}$ is the scatting coefficient at wavelength of maximum adsorption.

\section{Color measurement}

The color yield of the dyed sample was evaluated by using Colorflex Hunter Lab based on CIE system (International Commission on Illumination). The reference illuminant was D65 (Standard daylight), expressed as $L^{*}$ which represents lightness, $a^{*}$ represents redness $\left(+a^{*}\right)$ and greenness $\left(-a^{*}\right)$ and $\mathrm{b}^{*}$ represents yellowness $\left(+b^{*}\right)$ and blueness $\left(-b^{*}\right)$. From the $\mathrm{L}^{*}, \mathrm{a}^{*}$ and $\mathrm{b}^{*}$ coordinates, Chroma $\left(\mathrm{C}^{*}\right)$ values were calculated by using the following equation:

$C^{*}=\sqrt{ }\left(a^{* 2}+b^{* 2}\right)$

Chroma measures the intensity or saturation of the colorant.

\section{Color fastness tests}

The dyed cotton and wool fabrics were evaluated to color fastness to light (ISO 105 B02-2013), washing (ISO: 105C06:2010) and perspiration (ISO 105 E04-2013) using standard ISO methods.

\section{Results and Discussions}

To compare the conventional and ultrasonic dyeing method and assess the fastness properties of two methods, the cotton and wool fabric were dyed with four different mordants in both ultrasonic and conventional methods. The optimized dyeing condition for both cotton and wool has been furnished in Table 1 and 2. The maximum percentage of dye was absorbed at dye extraction $\mathrm{pH} 8$, dye extraction time 60 minutes and dye extraction temperature $60^{\circ} \mathrm{C}$. The maximum dye was absorbed at dye material concentration $5 \mathrm{gm} / \mathrm{gm}$ of fabric, dyeing $\mathrm{pH} 5$, dyeing temperature $60^{\circ} \mathrm{C}$ and dyeing time 90 minutes on cotton. The dye absorption percentage was found to be maximum at dyeing $\mathrm{pH}$ of 4 using dye concentration of $1 \mathrm{gm} / \mathrm{gm}$ of fabric, dyeing temperature $60^{\circ} \mathrm{C}$ and dyeing time 45 minutes on wool. Therefore, these conditions were considered to be optimum and were used for further dyeing purposes. When compared the optimum value of conventional and ultrasonic dyeing techniques, there is no much difference in dyeing conditions except the dyeing $\mathrm{pH}$ and dyeing temperature.

Table 1: Optimized dye extraction conditions

\begin{tabular}{|c|c|c|}
\hline \multicolumn{3}{|c|}{ Optimum value } \\
\hline Dye extraction conditions & Conventional dyeing techniques & Ultrasonic dyeing techniques \\
\hline Dye extraction $\mathrm{pH}$ & 7 & 6 \\
\hline Dye extraction time (min.) & 60 & 60 \\
\hline Dye extraction temperature $\left({ }^{\circ} \mathrm{C}\right)$ & 100 & 60 \\
\hline
\end{tabular}

Table 2: Optimized dyeing conditions

\begin{tabular}{|c|c|c|c|c|}
\hline \multicolumn{5}{|c|}{ Optimum value } \\
\hline \multirow{2}{*}{ Dyeing conditions } & \multicolumn{2}{|c|}{ Conventional dyeing techniques } & \multicolumn{2}{c|}{ Ultrasonic dyeing techniques } \\
\cline { 2 - 5 } & Cotton & Wool & Cotton & 1 \\
\hline Dye concentration $(\mathrm{g} / \mathrm{g})$ & 5 & 1 & 5 & 4 \\
\hline Dyeing $\mathrm{pH}$ & 7 & 7 & 6 & 60 \\
\hline Dyeing temperature $\left({ }^{\circ} \mathrm{C}\right)$ & 100 & 100 & 60 & 45 \\
\hline Dyeing time $(\min )$. & 90 & 45 & 90 & \\
\hline
\end{tabular}

The optimum mordant concentration values have been presented in Table 3. The optimum value for amla was found to be 0.5 on both cotton and wool and babool was found to be 0.4 on cotton and 0.5 on wool, for alum it was 10 on both cotton and wool and 2 and 4 on cotton and wool for tannic acid. There is no such different in optimized mordant concentration value in both the dyeing techniques. But in case of cotton, there is reduction in alum concentration value in ultrasonic dyeing techniques.

Table 3: Optimum mordant concentrations:

\begin{tabular}{|c|c|c|c|c|}
\hline \multicolumn{4}{|c|}{ Optimum value } \\
\hline \multirow{2}{*}{ Mordants } & \multicolumn{3}{|c|}{ Conventional dyeing techniques } & \multicolumn{2}{c|}{ Ultrasonic dyeing techniques } \\
\cline { 2 - 5 } & Cotton & Wool & Cotton & 0.5 \\
\hline Amla & 0.5 & 0.5 & 0.5 & 0.2 \\
\hline Babool & 0.4 & 0.2 & 0.4 & 10 \\
\hline Alum & 15 & 10 & 10 & 4.0 \\
\hline Tannic acid & 2.0 & 4.0 & 2.0 & \\
\hline
\end{tabular}

The higher K/S values of all the ultrasonic cotton dyed samples as shown in Figure 1 revealed that color strength were higher as compared to conventional dyed samples. The maximum K/S value was found to be higher in amla mordanted samples followed by alum, babool, unmordanted and tannic acid for both conventional and ultrasonic dyeing methods.
In case of wool, the K/S value was found to be maximum in the samples mordanted with amla followed by tannic acid, babool, unmordanted and alum by using both the ultrasonic and conventional dyeing techniques as shown in Figure 2. Similarly, the ultrasonic dyed samples have maximum color strength as compared to conventional dyed samples. Samples mordanted with alum have minimum color strength as 
compared to unmordanted sample by using both dyeing methods. An ultrasonic dyeing technique gave good color strength because ultrasonic energy breaks the aggregation of dye molecules at fibre surface and established equilibrium in a shorter time period.

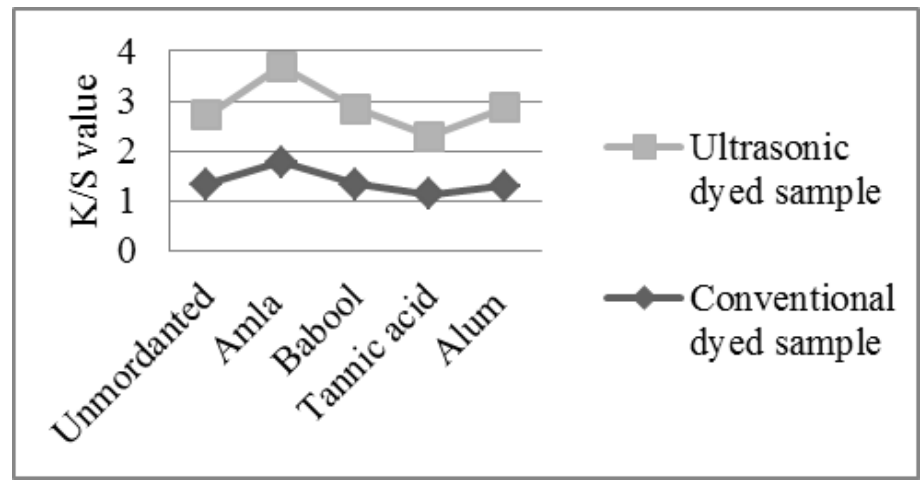

Fig. 1: Effect of ultrasonic dyeing techniques on K/S value of samples dyed with Arjun tree bark dye on cotton

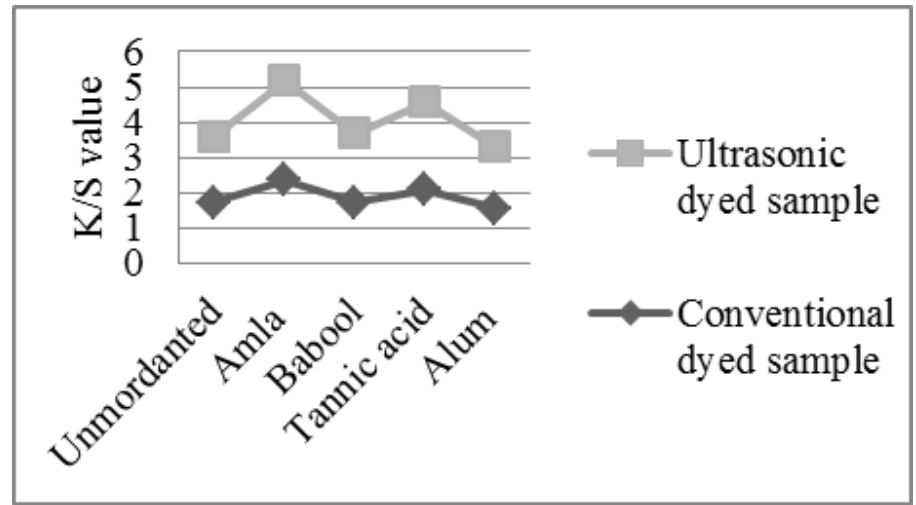

Fig. 2: Effect of ultrasonic dyeing techniques on K/S value of samples dyed with Arjun tree bark dye on wool

The CIE Lab values of both the conventional as well as ultrasonic dyed samples using four different mordants have been given in the Table 4 and Table 5 . The table reveals that the $\mathrm{L}^{*}$ value of ultrasonic dyed samples was less than the conventional dyed samples for unmordanted sample and samples mordanted with amla, babool, alum and tannic acid, which indicate that the ultrasonic dyed samples are darker in color. The reason may be due to acceleration of dye movement from solution to a fibre by ultrasound energy and reaction take place between dye molecules and fibre molecules.

The high $a^{*}$ value of ultrasonic dyed samples for unmordanted and those mordanted with all the four mordants as compared to the conventional dyed samples indicate that the ultrasonic dyed samples were more red. Whereas, the high $b^{*}$ value of ultrasonic dyed samples for unmordanted, mordanted with amla, babool, alum and tannic acid as compared to the conventional dyed samples indicate that the ultrasonic dyed samples were more yellow.

The higher $\mathrm{C}^{*}$ values for ultrasonic dyed samples, unmordanted and those mordanted with amla, babool, alum and tannic acid are indicative of the fact that the ultrasonic dyed samples were more saturated and brighter as compared to the conventional dyed samples.

Table 4: Chromaticity values of the dyed cotton fabrics

\begin{tabular}{|c|c|c|c|c|c|c|c|c|}
\hline & \multicolumn{2}{|c|}{$\mathbf{L}^{*}$} & \multicolumn{2}{|c|}{$\mathbf{a}^{*}$} & \multicolumn{3}{|c|}{$\mathbf{b}^{*}$} & \multicolumn{2}{c|}{$\mathbf{C}^{*}$} \\
\hline Samples & $\mathbf{C ~ D}$ & $\mathbf{U}$ D & $\mathbf{C ~ D}$ & $\mathbf{U} \mathbf{D}$ & $\mathbf{C ~ D}$ & $\mathbf{U}$ D & C D & U D \\
\hline Unmordanted & 68.88 & 66.39 & 5.59 & 8.86 & 15.31 & 15.88 & 16.83 & 17.68 \\
\hline Amla & 67.99 & 64.51 & 5.23 & 8.12 & 16.14 & 18.10 & 16.96 & 19.83 \\
\hline Babool & 72.52 & 68.43 & 3.68 & 6.69 & 14.61 & 15.52 & 15.07 & 16.90 \\
\hline Alum & 62.19 & 60.57 & 8.45 & 9.25 & 20.17 & 22.17 & 21.87 & 24.02 \\
\hline Tannic acid & 75.46 & 73.98 & 0.42 & 2.17 & 14.14 & 15.77 & 14.30 & 15.77 \\
\hline
\end{tabular}

CD: Conventionally Dyed sample, UD: Ultrasonic Dyed sample

Table 5: Chromaticity values of the dyed wool fabrics

\begin{tabular}{|c|c|c|c|c|c|c|c|c|}
\hline \multirow{2}{*}{ Samples } & \multicolumn{2}{|c|}{$\mathbf{L}^{*}$} & \multicolumn{2}{|c|}{$\mathbf{a}^{*}$} & \multicolumn{3}{|c|}{$\mathbf{b}^{*}$} & \multicolumn{2}{c|}{$\mathbf{C}^{*}$} \\
\cline { 2 - 9 } & $\mathbf{C ~ D}$ & $\mathbf{U} \mathbf{D}$ & $\mathbf{C ~ D}$ & $\mathbf{U} \mathbf{D}$ & $\mathbf{C ~ D}$ & $\mathbf{U} \mathbf{D}$ & $\mathbf{C ~ D}$ & $\mathbf{U} \mathbf{D}$ \\
\hline Unmordanted & 66.27 & 63.73 & 5.46 & 6.57 & 16.02 & 18.47 & 16.92 & 19.60 \\
\hline Amla & 63.37 & 57.98 & 1.52 & 5.84 & 35.59 & 38.19 & 35.62 & 38.63 \\
\hline Babool & 67.38 & 63.21 & 4.41 & 5.80 & 17.56 & 20.56 & 18.10 & 21.36 \\
\hline Alum & 67.80 & 67.22 & 4.07 & 4.72 & 18.08 & 18.69 & 18.53 & 19.28 \\
\hline Tannic Acid & 71.10 & 63.39 & 2.24 & 2.70 & 19.51 & 20.56 & 19.64 & 20.73 \\
\hline
\end{tabular}

CD: Conventionally Dyed sample, UD: Ultrasonic Dyed sample 
The color fastness grades of all the cotton samples, conventional and ultrasonic dyed are shown in Table 6. The light fastness grades were poor for the conventional dyed samples and they improved to fair and fairly good when these were dyed by using ultrasonic waves. The washing fastness grades in terms of color change were poor which improved to excellent because of ultrasonic waves. In terms of color staining, negligible or no staining was observed in all the cotton samples. The rubbing fastness grades regarding color change in both dry and wet condition were good in conventional dyed samples which improved to excellent in ultrasonic dyed samples. In wet condition the color staining improved from good to excellent due to dyeing with ultrasonic waves. In the case of perspiration fastness, in acidic media, the grades for color change improved from fairly good to excellent as a result of ultrasonic waves and same results were found for color staining in alkaline media.

Table 6: Color fastness grades of conventional and ultrasonic dyed cotton samples

\begin{tabular}{|c|c|c|c|c|c|c|c|c|c|c|c|c|c|c|}
\hline \multirow{4}{*}{$\begin{array}{c}\text { Sample } \\
\text { Unmordanted }\end{array}$} & \multirow[t]{4}{*}{ Light fastness grades } & \multicolumn{3}{|c|}{ Washing fastness grades } & \multicolumn{4}{|c|}{ Rubbing fastness grades } & \multicolumn{6}{|c|}{ Perspiration fastness grades } \\
\hline & & \multirow[t]{3}{*}{$\mathrm{CC}$} & \multicolumn{2}{|c|}{ CS } & \multicolumn{2}{|c|}{ Dry } & \multicolumn{2}{|c|}{ Wet } & \multicolumn{3}{|c|}{ Acidic } & \multicolumn{3}{|c|}{ Alkaline } \\
\hline & & & C & W & CC & CS & $\mathbf{C C}$ & CS & CC & C & & $\mathrm{CC}$ & & $\mathbf{S}$ \\
\hline & & & & & & & & & & $\mathbf{C}$ & $\mathbf{W}$ & & $\mathbf{C}$ & $\mathbf{W}$ \\
\hline CDS & 3 & $2 / 3$ & 5 & 5 & $4 / 5$ & $4 / 5$ & 4 & 4 & 4 & 5 & 5 & 4 & 4 & 5 \\
\hline UDS & $3 / 4$ & 3 & 5 & 5 & 5 & $4 / 5$ & 5 & $4 / 5$ & 4 & 5 & 5 & 4 & 4 & 5 \\
\hline \multicolumn{15}{|l|}{ Amla } \\
\hline CDS & 3 & 4 & 5 & 5 & 5 & 5 & 5 & 5 & 5 & $3 / 4$ & 5 & $4 / 5$ & 5 & 5 \\
\hline UDS & 4 & 4 & 5 & 5 & 5 & 5 & 5 & 5 & 5 & 4 & 5 & 5 & 5 & 5 \\
\hline \multicolumn{15}{|l|}{ Babool } \\
\hline CDS & $2 / 3$ & 4 & 5 & 5 & 5 & 5 & 5 & 5 & 5 & $4 / 5$ & 5 & 5 & 5 & 5 \\
\hline UDS & 3 & 4 & 5 & 5 & 5 & 5 & 5 & 5 & 5 & 5 & 5 & 5 & 5 & 5 \\
\hline \multicolumn{15}{|l|}{ Alum } \\
\hline CDS & $2 / 3$ & $2 / 3$ & 5 & 5 & 4 & 5 & 4 & 3 & 5 & 5 & 5 & 5 & 5 & 5 \\
\hline UDS & 3 & 3 & 5 & 5 & 5 & 5 & 5 & 4 & 5 & 4 & 5 & 5 & 5 & 5 \\
\hline \multicolumn{15}{|l|}{ Tannic acid } \\
\hline CDS & $2 / 3$ & 4 & 5 & 4 & 5 & 4 & 3 & 4 & 5 & 4 & 5 & 5 & 4 & 4 \\
\hline UDS & $2 / 3$ & $4 / 5$ & 5 & 4 & 5 & 5 & 4 & $4 / 5$ & 5 & 4 & 5 & 5 & 4 & 5 \\
\hline
\end{tabular}

$\mathrm{C}=$ Cotton, $\mathrm{W}=$ Wool, $\mathrm{CC}=$ Color Change, $\mathrm{CS}=$ Color Staining, $\mathrm{CDS}=$ Conventional Dyed Sample, UDS =Ultrasonic Dyed Sample

Table 7 reveals the color fastness of dyed wool samples. The light fastness grades of all the samples dyed using conventional method were 2 , indicating poor light fastness and it did not improve by using ultrasonic dyeing technique. But in case of tannic acid mordanted wool sample, the light fastness grade was improved by using ultrasonic waves. The washing fastness grades in terms of colour change were good which improved to excellent because of ultrasonic waves. In conventionally dyed samples, noticeable staining (3) was observed which improved to slight staining (4) in ultrasonic dyed samples. Similarly, the rubbing and perspiration fastness grades of dyed wool samples improved by ultrasonic dyeing method.

Table 7: Color fastness grades for conventional and ultrasonic dyed wool samples

\begin{tabular}{|c|c|c|c|c|c|c|c|c|c|c|c|c|c|c|}
\hline \multirow{4}{*}{$\begin{array}{c}\text { Sample } \\
\text { Unmordanted }\end{array}$} & \multirow{4}{*}{ Light fastness grades } & \multicolumn{3}{|c|}{ Washing fastness grades } & \multicolumn{4}{|c|}{ Rubbing fastness grades } & \multicolumn{6}{|c|}{ Perspiration fastness grades } \\
\hline & & \multirow[t]{3}{*}{$\mathrm{CC}$} & \multicolumn{2}{|c|}{ CS } & \multicolumn{2}{|c|}{ Dry } & \multicolumn{2}{|c|}{ Wet } & \multicolumn{3}{|c|}{ Acidic } & \multicolumn{3}{|c|}{ Alkaline } \\
\hline & & & \multirow[t]{2}{*}{$\mathbf{C}$} & \multirow[t]{2}{*}{$\mathbf{W}$} & \multirow[t]{2}{*}{$\mathbf{C C}$} & \multirow[t]{2}{*}{ CS } & \multirow[t]{2}{*}{$\mathbf{C C}$} & \multirow[t]{2}{*}{ CS } & \multirow[t]{2}{*}{$\mathbf{C C}$} & \multicolumn{2}{|c|}{ CS } & \multirow[t]{2}{*}{$\mathbf{C C}$} & \multicolumn{2}{|c|}{ CS } \\
\hline & & & & & & & & & & $\mathbf{C}$ & $\mathbf{W}$ & & $\mathbf{C}$ & $\mathbf{W}$ \\
\hline CDS & 2 & $4 / 5$ & 5 & 5 & 5 & 5 & 5 & $4 / 5$ & 5 & 5 & 5 & $4 / 5$ & $4 / 5$ & 5 \\
\hline UDS & 2 & $4 / 5$ & 5 & 5 & 5 & 5 & 5 & 5 & 5 & 5 & 5 & 5 & 5 & 5 \\
\hline \multicolumn{15}{|l|}{ Amla } \\
\hline CDS & 2 & $4 / 5$ & 5 & 5 & 5 & 5 & 5 & $4 / 5$ & $4 / 5$ & 5 & 4 & 4 & $4 / 5$ & 5 \\
\hline UDS & 2 & 5 & 5 & 5 & 5 & 5 & 5 & 5 & 5 & 5 & 5 & 5 & 5 & 5 \\
\hline \multicolumn{15}{|l|}{ Babool } \\
\hline CDS & 2 & 5 & 4 & 5 & 5 & 5 & 5 & 5 & 5 & $4 / 5$ & 5 & 5 & 5 & 5 \\
\hline UDS & 2 & 5 & 5 & 5 & 5 & 5 & 5 & 5 & 5 & 5 & 5 & 5 & 5 & 5 \\
\hline \multicolumn{15}{|l|}{ Alum } \\
\hline CDS & 2 & $4 / 5$ & 3 & 5 & $4 / 5$ & $4 / 5$ & $3 / 4$ & $4 / 5$ & 5 & $4 / 5$ & 5 & 4 & 5 & 5 \\
\hline UDS & 2 & 5 & 4 & 5 & 5 & 5 & 4 & 5 & 5 & 5 & 5 & 5 & 5 & 5 \\
\hline \multicolumn{15}{|l|}{ Tannic acid } \\
\hline CDS & 2 & 4 & $3 / 4$ & 4 & 4 & 4 & $3 / 4$ & $4 / 5$ & 5 & 5 & 5 & 5 & 5 & 5 \\
\hline UDS & 3 & 5 & $3 / 4$ & 5 & $4 / 5$ & 5 & 4 & 5 & 5 & 5 & 5 & 5 & 5 & 5 \\
\hline
\end{tabular}

$\mathrm{C}=$ Cotton, $\mathrm{W}=$ Wool, $\mathrm{CC}=$ Color Change, $\mathrm{CS}=$ Color Staining, $\mathrm{CDS}=$ Conventional Dyed Sample, UDS =Ultrasonic Dyed Sample

\section{Conclusion}

The use of ultrasonic dyeing technique for the dyeing of cotton and wool fabrics with barks of arjun dye (Terminalia arjuna) using mordants was found to have significant improvement in the dye absorption percentages. In addition to advantage of dye absorption, fabrics dyed by using ultrasonic dyeing methods showed a deeper shade, more saturated and good colour intensity. The ultrasonic wave also led to slight improvement in the light, washing, rubbing and perspiration fastness grades of the dyed samples. Hence, arjun dye can be successfully used for dyeing cotton and wool with better dyeing and fastness properties using ultrasonic dyeing method. This technique in addition to improving dye-uptake 
has an advantage of saving the energy which offers better environmental impact.

\section{Acknowledgement}

The authors are grateful to the Department of Apparel and Textile Science, Punjab Agricultural University, Ludhiana, Punjab for provision of research facilities and support.

\section{References}

1. Anna H, Christian RV. The potential use of organically grown dye plants in the organic textile industry. Journal of Sustain Agriculture. 2003; 23(2):17-40.

2. Ferreira ESB, Hulme AN, Macnab H, Ouve A. The natural constituents of historical textile dyes. Chemical Society Reviews. 2004; 33(6):329-336.

3. Ali MA, Almahy HA, Band AAA. Extraction of carotenoids as natural dyes from the Daucus carota Linn (carrot) using ultrasound in Kingdom of Saudi Arabia.Research Journal of Chemical Sciences. 2013; 3(1):63-66.

4. Padma SV. Chemistry of Natural Dyes, General Article. Resonance, 2000, 73-80.

5. Adeel S, Ghaffar A, Mushtaq M, Yameen M, Rehman FU, Zuber M et al. Bio-processing of Surface oxidized cellulosic fibre by microwave treatment for eco-friendly textile dyeing. Oxidation Communication. 2016; 39(3):2222-2396.

6. Baaka N, Haddar W, Ticha MB, Amorim MTP, M'Henni MF. Sustainability issues of ultrasonic wool dyeing with grape pomace colourant. Natural Product Research. 2016; 31(14):1655-1662.

7. Haji A, Mehrizi MK, Sharifzadeh J. Dyeing of wool with aqueous extract of cotton pods improved by plasma treatment and chitosan: Optimization using response surface methodology. Fibers and Polymers. 2016; 17(9):1480-1488.

8. Adeel S, Gulzar T, Azeem M, Saeed M, Hanif I, Iqbal N. Appraisal of marigold flower based lutein as natural colourant for textile dyeing under the influence of gamma radiations. Radiation Physics and Chemistry. 2017; 130:35-39.

9. Wang C, Xu C, Tian A, Fu S, Wang C. Extraction of natural dyes from Alpinia Blepharocalyx K. Schum for dyeing of silk fabrics. Coloration technology. 2013; 129:32-28.

10. Asma FZ, Rodiah MH, Aziah MY, Norakma MN, Nurhafizah I. Ultrasound-Assisted Extraction of Natural Dye from Exocarp and Mesocarp of Cocos nucifera. Advance Materials Research. 2015; 1113:477- 480.

11. Mansour HF, Heffernan S. Environmental aspects on dyeing silk fabric with sticta coronata lichen using ultrasonic energy and mild mordants. Clean Technologies and Environmental Policy. 2011; 13(1):207-213.

12. Sinha K, Aikat K, Das P, Datta S. Dyeing of modified cotton fiber with natural T erminalia arjuna dye: Optimization of dyeing parameters using response surface methodology. Environmental Progress and Sustainable Energy. 2016; 35:719-728.

13. Mandal S, Patra A, Samanta A, Roy S, Mandal A, Mahapatra TD et al. Analysis of phytochemical profile of Terminalia arjuna bark extract with antioxidative and antimicrobial properties. Asian Pacific Journal of Tropical Biomedicine. 2013; 3(12):960-966.

14. Mandal A, Das K, Nandi DK. In vitro bioactivity study of bark extract of Terminalia arjuna on probiotics, commercially available probiotic formulation. International Journal of Phytopharmacology. 2010; 1(2):109-113.

15. Das K, Chakraborty PP, Ghosh D, Nandi DK. Protective effect of aqueous extract of Terminalia arjuna against dehydrating induced oxidative stress and uremia in male rat. Iran Journal of Pharmacy Research. 2010; 9(2):153161.

16. Prabhavathi R, Devi DAS, Anitha DD. Improving the colour fastness of the selected natural Dyes on Cotton. Journal of Polymer and Textile Engineering. 2014; 1(4):21-26.

17. Bains S, Singh OP, Goraya G, Kang M. Dyeing of cotton with Arjun (Arjun terminalia) dye. Man Made Textile in India. 2002; 45(8):315-318.

18. Bains S, Singh OP, Goraya G, Kang M. Dyeing of cotton with goldendrop. (Onosma echoides) dye. Journal of Textile Association. 2002; 64(1):183-186.

19. Bains S, Kaur K, Kang S. Comparative study of colour fastness properties of dyed cotton with Arjun (Arjuna terminalia) dye using mordants and their combinations. Textile Trends. 2006; 59(2):41-44. 